\title{
Circuit
}

Musiques contemporaines

\section{Quelques éléments biographiques des fondateurs de Réseaux}

\section{Réjean Beaucage}

Volume 16, numéro 3, 2006

À musique contemporaine, supports contemporains?

URI : https://id.erudit.org/iderudit/902418ar

DOI : https://doi.org/10.7202/902418ar

Aller au sommaire du numéro

Éditeur(s)

Les Presses de l'Université de Montréal

ISSN

1183-1693 (imprimé)

1488-9692 (numérique)

Découvrir la revue

Citer ce document

Beaucage, R. (2006). Quelques éléments biographiques des fondateurs de Réseaux. Circuit, 16(3), 117-118. https://doi.org/10.7202/902418ar d'utilisation que vous pouvez consulter en ligne.

https://apropos.erudit.org/fr/usagers/politique-dutilisation/ 


\section{Quelques éléments biographiques des fondateurs de Réseaux}

par RéJean Beaucage

\section{Robert Normandeau (1955, Québec)}

Premier récipiendaire d'un doctorat (1992) en composition électroacoustique de l'Université de Montréal (sous la direction de Marcelle Deschênes et Francis Dhomont), Robert Normandeau est de ceux qui ont largement contribué à ce que l'on puisse parler aujourd'hui d'une "école québécoise" d'électroacoustique, sa musique s'étant distinguée à de nombreuses reprises dans les plus grands festivals et concours internationaux. Membre de l'ACREQ de 1986 à 1993, il y a produit la série de concerts Clair de terre, donnée au Planétarium de Montréal. Clair de terre est aussi le titre de son plus récent disque, le quatrième paru chez Empreintes DIGITALes. II compte parmi les fondateurs de la Communauté électroacoustique canadienne (CEC) en 1986, un organisme qui venait combler le besoin des compositeurs de se regrouper.

Compositeur très actif, il s'est vu remettre en 1999 le prix Opus du Conseil québécois de la musique dans la catégorie compositeur de l'année. Son travail, du côté de la musique de concert, s'inscrit dans l'optique d'un cinéma pour l'oreille. Ces dernières années, il a produit plusieurs musiques pour le théâtre.

\section{Gilles Gobeil (1954, Sorel)}

Son premier disque paraît la même année que celui de Robert Normandeau et, comme lui, il a complété une maîtrise en composition à l'Université de Montréal et reçu de très nombreuses distinctions internationales, mais là s'arrêtent les similitudes entre ces deux artistes aux esthétiques bien différentes. Gobeil ne dédaigne pas la musique mixte et compte de ce côté quelques réalisations qui sont autant de réussites (voir son travail avec l'ondiste Suzanne Binet-Audet ou avec le guitariste René Lussier). II a d'ailleurs composé en collaboration avec Lussier la pièce Le contrat, basée sur le mythe de Faust; un tour de force compositionnel à l'intérieur duquel chacun des compositeurs réussit à conserver son âme. Le style de Gilles Gobeil, très personnel, est assez noir et d'une véhémence qui contraste totalement avec la personnalité calme et posée du compositeur. Son univers musical est peuplé de sonorités biomécaniques et industrielles qui stimulent l'imagination de l'auditeur, tant ce monde futuriste offre peu de références. Sa musique se caractérise en outre par une très grande maîtrise des outils de manipulation du 
son, rendue avec une présence peu commune. Lors de la remise des prix Opus 2004-2005 du Conseil québécois de la musique, son disque Trilogie d'ondes (Empreintes DIGITALes) était nommé "Disque de l'année - musiques actuelle, électroacoustique".

\section{Jean-François Denis (1960, Montréal)}

Infatigable promoteur de la musique électroacoustique, Jean-François Denis est détenteur d'une maîtrise en musique électronique du Mills College d'Oakland. Entre 1982 et 1990, il compose une trentaine d'œuvres instrumentales ou électroacoustiques. Parmi ces dernières, plusieurs sont interprétées en direct, seul ou en ensemble. Il enseigne l'électroacoustique à l'Université Concordia de 1985 à 1989 et y organise les séries de concerts du Groupe électroacoustique de Concordia (GEC). Membre fondateur et premier président de la Communauté électroacoustique canadienne, il y a dirigé de nombreuses publications. Sa carrière de compositeur s'estompe au début des années 1990 alors qu'il fonde avec Claude Shryer l'étiquette de disques Empreintes DIGITALes (premier lancement le 30 janvier 1990 avec un disque de Christian Calon). Par ce moyen, il contribue très largement à faire rayonner la musique des compositeurs d'ici à l'étranger, à la faire mieux connaître chez nous et à faire connaître au Québec celle des grands compositeurs d'ailleurs. Avec la maison de distribution DIFFUSION i MéDIA/electrocd.com, qu'il fonde simultanément, il donne une meilleure visibilité à de petites étiquettes de "musiques difficiles" et prend une place incontournable dans le marché du disque au Québec. La Liste (<www.laliste.qc.ca>), qu'il lance vers 1992, regroupe bon nombre des organismes culturels montréalais œuvrant en musiques contemporaine, électroacoustique et actuelle dans un effort d'organisation des horaires de concerts et d'information du public. 